\title{
MiCE FEEDING ON SARRACENIA SECRETION
}

\section{DON GRAY•Auckland• New Zealand•don.gray@xtra.co.nz}

This story started a couple of years back when I arrived at my New Zealand greenhouse and found a pair of native nectar feeding birds we call wax eyes (Zosterops lateralis) flying along the inside of the greenhouse and hanging around a group of autumn Sarracenia leucophylla pitchers. I managed to take a couple of very average photos of the wax eyes feeding from the mouths of the S. leucophylla.

One season later, I was "working" in the greenhouse on my sun lounger when a mouse appeared about 2 meters away and ran along the frame of a bog constructed on the floor next to where I was sitting containing Sarracenia. The mouse then climbed up into the bog and I could track its progress by the movement of foliage as it made its way through the various pots. The mouse then reappeared, climbing straight up the side of a S. leucophylla trumpet and proceeded to lick the areas of the pitcher rim, mouth, inner hood, and down into the trumpet. The mouse took its time making sure all the nectar was taken. It then proceeded back down to the pot and up an adjoining pitcher continuing the same feeding pattern. There was frustration involved in this as I knew if I moved it would scare the mouse and any photo opportunity would be gone. In any case I didn't have my camera within arm's reach.

I have witnessed this behaviour on various occasions since that first encounter a year ago, but was never able to have a camera handy at just the right time. Like all wild mice these are a skittery bunch and run for it when they detect movement.

By chance on Saturday $25^{\text {th }}$ May 2013, a well-known CP grower, Heather Frederick, was visiting my Sarracenia collection for the first time. We were only a few minutes into the visit when Heather called out and said she'd spotted either a rat or mouse moving through one of the ground bogs. I told Heather there was no problem as rodents commonly frequented the ground bogs to feed from the mouths of the Sarracenia. I advised Heather they were not easy to approach and not to bother trying to take photos as they would run off. In the meantime, Heather already had her camera out and was taking photos and videos of the event! I then retreated back to my camera bag and when I returned, Heather was still taking photos of the feeding rodent. Presumably having had enough the mouse eventually disappeared.

I'm not sure if this behaviour of mice feeding from Sarracenia as been recorded or photographed before. Thankfully my photos came out OK. It was a highlight of the visit for both myself and Heather and we are keen to hear from other CP enthusiast/researchers who may have experience or knowledge of rodents feeding on Sarracenia secretions.

The rodent in these photos is Mus musculus, commonly known as either the house mouse or field mouse. It is the sole species of mouse in New Zealand having been introduced by Europeans circa 1830. All rodents in New Zealand are introduced.
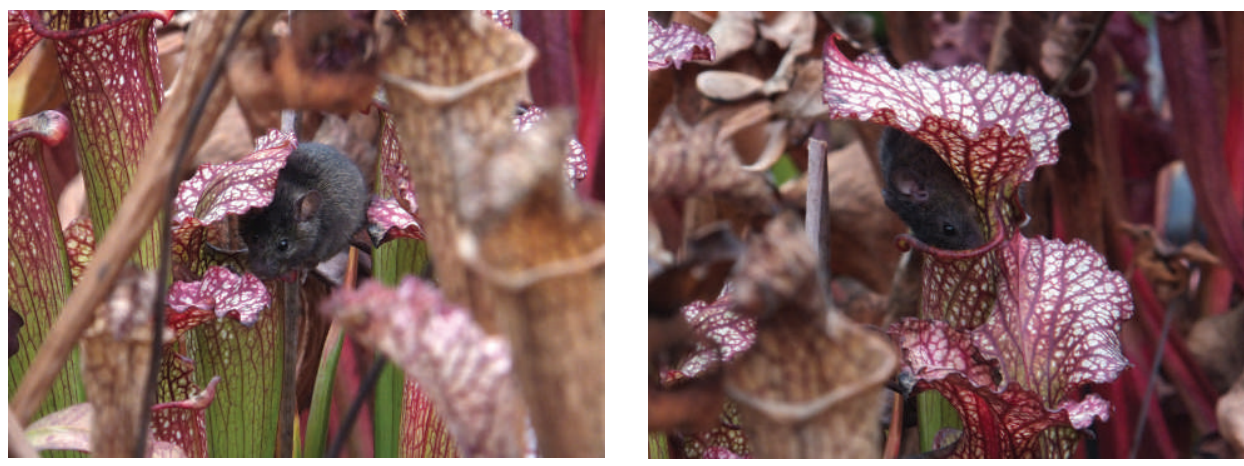